\title{
Primitive ATP-activated P2X receptors: discovery, function and pharmacology
}

\author{
Samuel J. Fountain* \\ School of Biological Sciences, University of East Anglia, Norwich, UK
}

\section{Edited by:}

Geoffrey Burnstock, University

College Medical School, UK

\section{Reviewed by:}

Alexej Verkhratsky, University of

Manchester, UK

Steven Ennion, University of

Leicester, UK

*Correspondence:

Samuel J. Fountain, School of Biological Sciences, University of East Anglia, Norwich Research Park, Norwich NR4 7TJ, UK

e-mail:s.j.fountain@uea.ac.uk
Adenosine 5-triphosphate (ATP) is omnipresent in biology. It is therefore no surprise that organisms have evolved multifaceted roles for ATP, exploiting its abundance and restriction of passive diffusion across biological membranes. A striking role is the emergence of ATP as a bona fide transmitter molecule, whereby the movement of ATP across membranes serves as a chemical message through a direct ligand-receptor interaction. P2X receptors are ligand-gated ion channels that mediate fast responses to the transmitter ATP in mammalian cells including central and sensory neurons, vascular smooth muscle, endothelium, and leukocytes. Molecular cloning of P2X receptors and our understanding of structure-function relationships has provided sequence information with which to query an exponentially expanding wealth of genome sequence information including protist, early animal and human pathogen genomes. P2X receptors have now been cloned and characterized from a number of simple organisms. Such work has led to surprising new cellular roles for the P2X receptors family and an unusual phylogeny, with organisms such as Drosophila and C. elegans notably lacking P2X receptors despite retaining ionotropic receptors for other common transmitters that are present in mammals. This review will summarize current work on the evolutionary biology of P2X receptors and ATP as a signaling molecule, discuss what can be drawn from such studies when considering the action of ATP in higher animals and plants, and outline how simple organisms may be exploited experimentally to inform $\mathrm{P} 2 \mathrm{X}$ receptor function in a wider context.

Keywords: P2X receptor, evolution, molecular, pharmacology, structure-activity relationship, ion channels

\section{INTRODUCTION}

Seminal early discoveries identified the role of acetylcholine and norepinephrine in chemical transmission at neuronal synapse. However, the concept of non-adrenergic non-cholinergic (NANC) chemical transmission mediated by adenosine 5 -triphosphate (ATP) emerged much later and was met initially with sizable resistance amongst the pharmacology and neuroscience communities (Burnstock, 2012). The development of the hypothesis that ATP can act as a transmitter molecule also came to challenge "Dales Principle" which suggested that a neuron only utilizes one transmitter molecule to communicate. It is now well accepted that neurons of the central and peripheral nervous systems release ATP as a co-transmitter. Indeed ATP is the sole transmitter molecule to act post-synaptically in some instances, for example during sympathetic innervation of submucosal arterioles of the intestine (Evans and Surprenant, 1992). Some molecules that are associated with neurotransmission such as GABA and glutamate are utilized by primitive organisms, which lack nervous systems, for the purpose of cellular signaling (Fountain, 2010).

The human genome encodes a family of cell surface receptors that are activated by extracellular adenine and uridine signaling nucleotides. The metabotropic arm of this family are the G protein-coupled P2Y (mammalian P2 $\mathrm{Y}_{1,2,4,6,11,12,13,14}$ ) receptors that respond to ATP, ADP, UTP, UDP, and UDP-glucose with receptor subtype selectivity, and typically mediate slow responses to nucleotides. P2X receptors (mammalian $\mathrm{P} 2 \mathrm{X}_{1-7}$ ) are ligand-gated ion channels and mediate fast responses solely to ATP. In mammals, P2X receptor activation is associated with diverse physiological and pathophysiological processes including pain, inflammation, taste and smooth muscle contraction (Khakh and North, 2006). P2X receptors are non-selective cation channels, consequently receptor activation leads to membrane depolarization and cellular calcium influx, both by direct receptor permeation of calcium and voltage-gated calcium channel activation (North, 2002).

Adenosine 5-triphosphate is omnipresent in biology and plays many important roles including energy transfer and as a phosphate donor in enzymatic reactions, though its acceptance as a certified signaling ligand was slow despite early reports of potent physiological action in mammalian systems. The effects of exogenous ATP on insects and invertebrates has been known for some time (for a review see Burnstock and Verkhratsky, 2009), though the identification and cloning of $\mathrm{P} 2 \mathrm{X}$ receptors from invertebrates and primitive single-celled organisms has been far less widespread. The identification of genes encoding putative $\mathrm{P} 2 \mathrm{X}$ receptors in primitive organisms has been aided by a wealth of structure-function information for mammalian receptors, and an ever-expanding library of curated genomes for single-celled organisms including algae, amoeba and basal fungi. For example, the $\mathrm{P} 2 \mathrm{X}_{\mathrm{A}}$ receptor of Dictyostelium discoideum shares only very low primary sequence homology with mammalian P2X receptors (Fountain et al., 2007). A translated BLAST search using the full-length 378 amino acid 
sequence of the Dictyostelium as a query, provide no homologous mammalian $\mathrm{P} 2 \mathrm{X}$ receptor sequences when using an expect value ( $E$ value) of 10. However, using the second transmembrane (TM2) domain as a search term returns hits of mammalian homologous, giving confidence of authenticity based on the conserved pattern of TM2 residues known to be critical to the function of mammalian P2X receptors. Bioinformatics is a powerful approach for expanding the phylogeny of primitive $\mathrm{P} 2 \mathrm{X}$ receptors, however, caution must be applied when making structural or functional inferences to mammalian P2X orthologues without cloning and definitive demonstration of functionality. This is because several cloned P2X receptors from primitive species fail to form functional ATP-activated channels (Fountain et al., 2008; Ludlow et al., 2009). This review will focus on the P2X receptor homologues cloned from invertebrate and primitive non-vertebrate organisms that have been shown definitively to be ATP activated ion channels through experimentation.

\section{CLONED NON-VERTEBRATE AND PRIMITIVE P2X RECEPTORS}

The pharmacological properties of cloned $\mathrm{P} 2 \mathrm{X}$ receptors are summarized in Tables 1 and 2.

\section{Schistosoma mansoni (TREMATODE)}

The first non-vertebrate $\mathrm{P} 2 \mathrm{X}$ receptor was cloned from the human pathogen S. mansoni. Schistosoma are parasitic blood fluke and are trematodes belonging to the platyhelminthe genus. S. mansoni infection in humans causes schistodomiasis, a chronic illness which can lead to severe damage of multiple organs. S. mansoni encodes a protein that has 26-37\% sequence homology with human $\mathrm{P}_{2} \mathrm{X}_{1}-\mathrm{P} 2 \mathrm{X}_{7}$. Expression in Xenopus oocytes produces an ATP activated ion channel ( $S c h \mathrm{P} 2 \mathrm{X})$ that responds to ATP with an $\mathrm{EC}_{50}$ of $22 \mu \mathrm{M}$ (Agboh et al., 2004). BzATP, a full agonist at mammalian $\mathrm{P}_{2} \mathrm{X}_{7}$ receptors, acts as a partial agonist at $\operatorname{Sch} \mathrm{P} 2 \mathrm{X}$ evoking a maximal response $75 \%$ that of ATP. Though less efficacious BzATP is more potent than ATP, evoking half-maximal responses at $4 \mu \mathrm{M}$. ATP evoked responses at $S c h \mathrm{P} 2 \mathrm{X}$ are inhibited by classical purinergic receptor antagonists PPADS and suramin

Table 1 | Agonist sensitivity of cloned P2X receptors.

\begin{tabular}{lllll}
\hline & ATP & \multicolumn{1}{c}{ BzATP } & \multicolumn{1}{c}{$\boldsymbol{\alpha} \boldsymbol{\beta}$ meATP } & \multicolumn{1}{c}{$\boldsymbol{\beta}$ yimidoATP } \\
\hline OtP2X & 250 & insensitive $(1 \mathrm{mM})$ & $>5 \mathrm{mM}$ & insensitive (1 mM) \\
$D d P 2 X_{A}$ & 97 & $(3 \mathrm{mM}, 25 \%)$ & 95 & 15 \\
$D d \mathrm{P} 2 \mathrm{X}_{\mathrm{B}}$ & 266 & $\mathrm{ND}$ & $\mathrm{ND}$ & 85 \\
$\operatorname{DdP} 2 \mathrm{X}_{\mathrm{E}}$ & 511 & $\mathrm{ND}$ & $\mathrm{ND}$ & $(3 \mathrm{mM}, 22 \%)$ \\
HdP2X & 45 & $12(65 \%)$ & $(100 \mu \mathrm{M}, 50 \%)$ & $\mathrm{ND}$ \\
BmP2X & 70 & $\mathrm{ND}$ & $\mathrm{ND}$ & $\mathrm{ND}$ \\
SchP2X & 22 & $4(75 \%)$ & $\mathrm{ND}$ & $\mathrm{ND}$ \\
LymP2X & 6 & $2(33 \%)$ & $(100 \mu \mathrm{M}, 37 \%)$ & $\mathrm{ND}$ \\
\hline
\end{tabular}

Values are given as approximates of reported $E C_{50}$ concentrations. $E C_{50}$ values are given as $\mu M$. ND indicates antagonist sensitivity not determined. Maximum responses for partial agonist are given in parenthesis as \% maximum ATP response. Where $E C_{50}$ values have not been determined experimentally maximum concentrations tested are given in parenthesis with response as \% maximum ATP response. with $\mathrm{IC}_{50}$ values of 4 and $10 \mu \mathrm{M}$, respectively. Permeability studies in HEK293 cells expressing $S c h$ P2X reveal a high permeability to calcium $\left(P_{\mathrm{Ca}} / P_{\mathrm{Na}}=3.8\right)$ that is comparable to mammalian $\mathrm{P} 2 \mathrm{X}$ receptors. Cation substitution experiments reveal $S c h \mathrm{P} 2 \mathrm{X}$ and mammalian P2X receptors have conserved ionic pore diameters. Praziquantel is a drug used in the treatment of schistodomiasis. Though the action of praziquantel is dependent upon affecting calcium homeostasis in worms (Kohn et al., 2001), praziquantel does not inhibit SchP2X (Agboh et al., 2004).

\section{Dictyostelium discoideum (AMOEBA)}

Dictyostelium discoideum, a soil-living amoeba, transitions from a community of unicellular amoebae into a multicellular fruiting body during its developmental lifecycle. This eukaryote belongs to the phylum Mycetozoa, emerging after plants and a common ancestor to fungi and animals. Dictyostelium amoeba display many animal cells traits including chemotaxis and phagocytosis. The chemical stimuli that govern the social behavior and complex development of Dictyostelium remain a subject of intense study. Prior to the discovery of ATP activated P2X receptors in Dictyostelium it was known that the neurotransmitters glutamate and GABA are important signaling cues governing cell fate and development in the organism (Fountain, 2010). The genome of Dictyostelium encodes five P2X receptor homologues $\left(D d \mathrm{P} 2 \mathrm{X}_{\mathrm{A}-\mathrm{E}}\right)$ that display low primary sequence homology with human $\mathrm{P} 2 \mathrm{X}$ receptors. The family of Dictyostelium $\mathrm{P} 2 \mathrm{X}$ receptors are the most extensively studied of the primitive $\mathrm{P} 2 \mathrm{X}$ receptor paralogues in terms of biophysics, structure-function and physiology. $D d \mathrm{P} 2 \mathrm{X}_{\mathrm{A}}, D d \mathrm{P} 2 \mathrm{X}_{\mathrm{B}}$, and $D d \mathrm{P} 2 \mathrm{X}_{\mathrm{E}}$ form functional ATP-activated ion channels when expressed in HEK293 cells or Xenopus oocytes (Fountain et al., 2007; Ludlow et al., 2009; Baines et al., 2013). ATP evoked currents can be detected in HEK293 cells expressing $D d \mathrm{P} 2 \mathrm{X}_{\mathrm{D}}$ under experimental conditions of low extracellular $\mathrm{Na}^{+}$(Baines et al., 2013), but $D d P 2 X_{C}$ expression fails to produce functional ion channels in either HEK293 or Xenopus oocytes (Ludlow etal., 2009; Baines etal., 2013). ATP is a full agonist at Dictyostelium $\mathrm{P} 2 \mathrm{X}$ receptors with $\mathrm{EC}_{50}$ values in the range 100-500 $\mu \mathrm{M} . D d \mathrm{P} 2 \mathrm{X}_{\mathrm{A}}$ receptors are most sensitive to ATP and $D d \mathrm{P} 2 \mathrm{X}_{\mathrm{E}}$ receptors least sensitive (Fountain et al., 2007; Ludlow et al., 2009; Baines et al., 2013). $\alpha \beta$ me-ATP is a full agonist of equal potency to ATP at P2X $\mathrm{X}_{\mathrm{A}}$ and BzATP act as a weak partial agonist (Fountain et al., 2007). Interestingly the hydrolysis resistant ATP analog $\beta$ rimido-ATP is a full agonist at $D d \mathrm{PX}_{\mathrm{A}}$ and $D d \mathrm{P} 2 \mathrm{X}_{\mathrm{B}}$ receptors with 3-10-fold greater potency than ATP (Fountain et al., 2007; Ludlow et al., 2009). $\beta$ yimido-ATP was found to act as a very weak agonist at $D d P 2 X_{\mathrm{E}}$ receptors. Dictyostelium $\mathrm{P} 2 \mathrm{X}$ receptors are freely permeable to $\mathrm{Na}^{+}, \mathrm{Ca}^{2+}\left(P_{\mathrm{Ca}} / P_{\mathrm{Na}}=1.5\right.$; Fountain et al., 2007), $\mathrm{K}^{+}\left(P_{\mathrm{K}} / P_{\mathrm{Ca}}=1.8-2.0\right.$; Ludlow et al., 2009), $\mathrm{NH}_{4}{ }^{+}\left(P_{\mathrm{NH} 4} / P_{\mathrm{Ca}}=1.8-2.0\right.$; Ludlow et al., 2009) and choline $\left(P_{\mathrm{K}} / P_{\mathrm{Ca}}=0.5-0.6\right.$; Fountain et al., 2007; Ludlow et al., 2009). In addition to a range of cations, $D d \mathrm{P} 2 \mathrm{X}_{\mathrm{A}}$ and $D d \mathrm{P} 2 \mathrm{X}_{\mathrm{B}}$ also freely permeate $\mathrm{Cl}^{-}$when expressed in Xenopus oocytes (Ludlow et al., 2009). Permeability to $\mathrm{Cl}^{-}$is an usual feature amongst P2X receptors, however, not unique. Chick and human $\mathrm{P}_{2} \mathrm{X}_{5}$ receptors are also reported to permeate $\mathrm{Cl}^{-}$(Ruppelt et al., 1999; Bo et al., 2003). Unlike mammalian P2X all Dictyostelium P2X receptors are insensitive to antagonism by suramin, PPADS or TNP-ATP (Fountain 
Table 2 | Antagonist sensitivity of cloned P2X receptors.

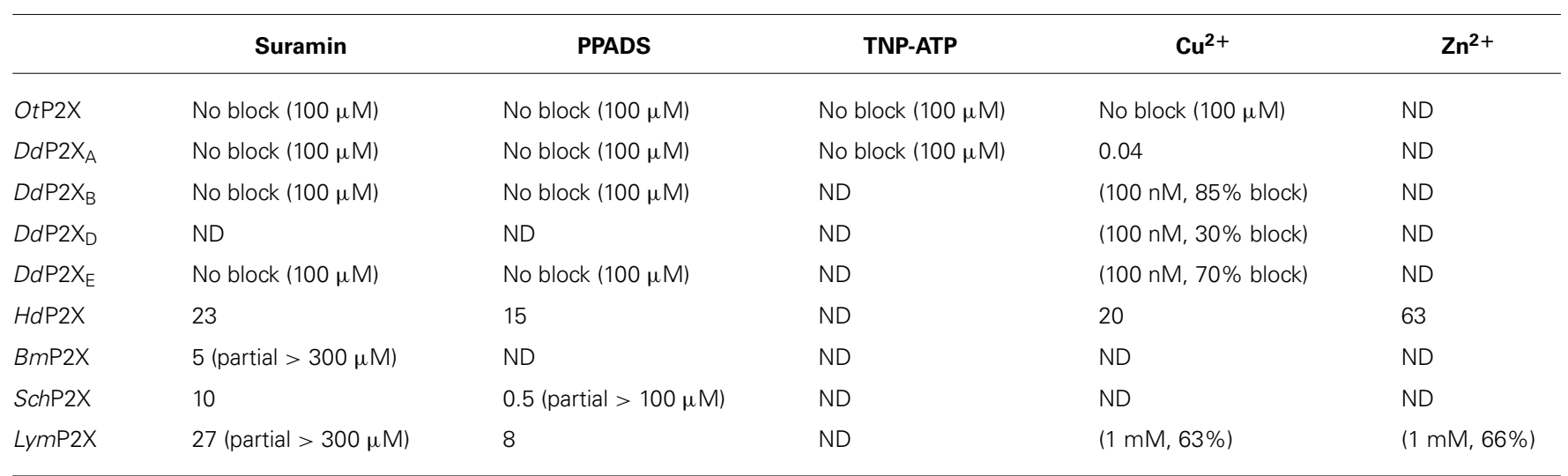

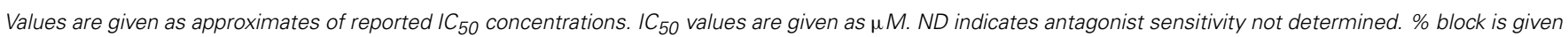
where an $I C_{50}$ value has not been determined.

et al., 2007; Ludlow et al., 2009). This makes Dictyostelium P2X receptors very useful tools for understanding antagonist action at $\mathrm{P} 2 \mathrm{X}$ receptors as the structural determinants of drug binding in $\mathrm{P} 2 \mathrm{X}$ receptors are poorly defined. A common feature shared by both Dictyostelium and mammalian P2X receptors is modulation by divalent metal ions (Virginio et al., 1997; Coddou et al., 2003). $\mathrm{Cu}^{2+}$ potently blocks $D d \mathrm{P} 2 \mathrm{X}_{\mathrm{A}}$ with a half-maximal inhibitory of $40 \mathrm{nM}$ (Fountain et al., 2007). $D d \mathrm{P} 2 \mathrm{X}_{\mathrm{B}}, D d \mathrm{P} 2 \mathrm{X}_{\mathrm{D}}$ and $D d \mathrm{P} 2 \mathrm{X}_{\mathrm{E}}$ are blocked to a varying degree $(30-85 \%)$ by $100 \mathrm{nM} \mathrm{Cu}^{2+} . \mathrm{Ni}^{2+}$ is less potent at blocking $D d \mathrm{P} 2 \mathrm{X}_{\mathrm{A}}$ currents $\left(\mathrm{IC}_{50} 60 \mu \mathrm{M}\right.$; Fountain et al., 2007).

The most striking feature of Dictyostelium P2X receptor functionality is their exclusive intracellular residence. Although some mammalian P2X receptors exist between intracellular compartments (Qureshi etal., 2007) and the plasma membrane Dictyostelium P2X receptors are targeted inside the cell. Several reports confirm that Dictyostelium P2X receptors reside on the contractile vacuole (Fountain et al., 2007; Ludlow et al., 2009), an osmoregulatory organelle and acidic calcium store (Heuser et al., 1993; Malchow et al., 2006; Sivaramakrishnan and Fountain, 2012). In a study by Fountain et al. (2007) Dictyostelium cells lacking $D d \mathrm{P} 2 \mathrm{X}_{\mathrm{A}}$ through genetic disruption were found to swell in response to hypotonic stress but lack any regulatory cell volume decrease, suggesting a severe impairment of contractile vacuole function. The phenotype was reconfirmed in a later study by Baines et al. (2013) who demonstrated that regulatory cell volume decrease could be rescued, or partially rescued, in $D d P 2 X_{A}$ knockout cells by overexpression of $D d \mathrm{P} 2 \mathrm{X}_{\mathrm{A}}, D d \mathrm{P} 2 \mathrm{X}_{\mathrm{B}}, D d \mathrm{P} 2 \mathrm{X}_{\mathrm{D}}$, or $D d \mathrm{P} 2 \mathrm{X}_{\mathrm{E}}$, but not $D d \mathrm{P} 2 \mathrm{X}_{\mathrm{C}}$ which fail to form functional ion channels when expressed in HEK293 or Xenopus oocytes (Ludlow et al., 2009; Baines etal., 2013). These data indicate a requirement for ATP activation of $\mathrm{P} 2 \mathrm{X}$ receptors for normal contractile vacuole function and osmoregulation. These findings are not in agreement with a study by Ludlow et al. (2009) who demonstrate that Dictyostelium lacking all five $\mathrm{P} 2 \mathrm{X}$ receptors still undergo regulatory cell volume decrease, despite a delay in recovery. The differences in phenotype reported can be explained by strain variance. In a recent side-by-side examination (Sivaramakrishnan and Fountain, 2013) of AX2 (used by Ludlow et al., 2009) and
AX4 (used by Fountain etal., 2007; Baines et al., 2013) laboratory strains of Dictyostelium, it was found that wild-type AX2 and AX4 vary in the degree of volume recovery following hypotonic swelling and that AX2 but not AX4 can tolerate loss of $D d \mathrm{P} 2 \mathrm{X}_{\mathrm{A}}$. Within the vacuolar membrane $\mathrm{P} 2 \mathrm{X}$ receptors are orientated such that the ATP binding site (ectodomain) faces the vacuole lumen, suggesting that the $\mathrm{P} 2 \mathrm{X}$ receptors are positioned to sense changes in luminal ATP. Experiments using purified vacuoles demonstrate that ATP can be translocated into the vacuole lumen, representing a possible mechanism of ATP accumulation (Sivaramakrishnan and Fountain, 2013). Addition of ATP to intact vacuole preparations causes release of stored calcium. The magnitude of calcium release is reduced in $D d \mathrm{P} 2 \mathrm{X}_{\mathrm{A}}$ knockout vacuoles and ablated in vacuoles lacking all five $\mathrm{P} 2 \mathrm{X}$ receptors. These data suggest that vacuoles respond to luminal ATP accumulation by releasing stored calcium via intracellular $\mathrm{P} 2 \mathrm{X}$ receptor activation (Sivaramakrishnan and Fountain, 2013). It remains unclear how $\mathrm{P} 2 \mathrm{X}$ receptor dependent calcium release contributes to contractile vacuole function though possibilities include facilitation of docking or vacuole fusion. Vesicular $\mathrm{P}_{2} \mathrm{X}_{4}$ receptor activation has been shown recently to facilitate vesicle fusion in mammalian cells in a calcium-dependent fashion (Miklavc et al., 2011; Thompson et al., 2013). Vacuoles isolated from AX2 amoeba release substantially less calcium in response to ATP in comparison to AX4 vacuoles, which may provide some mechanistic insight into the difference in $\mathrm{P} 2 \mathrm{X}$ receptor dependency for osmoregulation between the two strains (Sivaramakrishnan and Fountain, 2013).

Extracellular ATP is detectable in suspensions of Dictyostelium (Parish and Weibel, 1980). Early work demonstrated that application of extracellular ATP stimulates $\mathrm{Ca}^{2+}$ influx in Dictyostelium which was sensitive to the purinergic receptor antagonist suramin (Parish and Weibel, 1980). More recently this has been demonstrated using aqueorin expressing strains of Dictyostelium (Ludlow et al., 2008), though in this study the ATP evoked $\mathrm{Ca}^{2+}$ responses were insensitive to the $\mathrm{P} 2$ receptor antagonists suramin and PPADS but did display sensitivity to block by low micromolar $\mathrm{Cu}^{2+}$ as for the Dictyostelium $\mathrm{P} 2 \mathrm{X}_{\mathrm{A}}$ receptor (Fountain et al., 2007; Ludlow et al., 2009). Despite this, the ATP evoked calcium response remains intact following genetic knockout of all five $\mathrm{P} 2 \mathrm{X}$ receptors 
(P2X $\mathrm{X}_{\mathrm{A}-\mathrm{E}}$; Ludlow et al., 2009) suggesting the Dictyostelium P2X receptors do not mediate responses to extracellular ATP and supports their intracellular residency (Fountain et al., 2007; Ludlow et al., 2009; Sivaramakrishnan and Fountain, 2012).

\section{Ostreococcus tauri (ALGAE)}

Ostreococcus are primitive single celled algae and the smallest free-living eukaryotes. They belong to the Prasinophyceae class of unicellular green algae that mainly includes marine planktonic species, and are close to the evolutionary origins of photosynthesis. O. tauri encodes a protein of 387 amino acids termed OtP2X that shares $23 \%$ primary sequence identity with the Dictyostelium $\mathrm{P} 2 \mathrm{X}_{\mathrm{A}}$ receptor (Fountain et al., 2007) and around $28 \%$ identity with human $\mathrm{P} 2 \mathrm{X}$ receptors. Expression of $\mathrm{Ot} \mathrm{P} 2 \mathrm{X}-m y c$ in HEK293 cells produces a 50-kDa protein (Fountain et al., 2008). The receptor contains many of the residues considering important for mammalian $\mathrm{P} 2 \mathrm{X}$ receptor function, including conservation of ectodomain lysine residues are positions equivalent to Lys $^{69}$ and Lys $^{308}$ of rat P2X 2 , though overall the ectodomain is poorly conserved. The N-terminal YXTXK/R sequence is retained, however, the C-terminal YXXXK motif shown to promote membrane retention in mammalian receptors (Chaumont et al., 2004) is replaced with a YESWL sequence.

ATP evokes OtP2X channel opening with a half maximal concentration around $250 \mu \mathrm{M}$ and activation threshold of around $30 \mu \mathrm{M}$. Whole-cell currents display modest desensitization in the presence of ligand. Single channel analysis revealed that $\mathrm{O} t \mathrm{P} 2 \mathrm{X}$ open channel properties are flickery in nature (Fountain et al., 2008). $\alpha, \beta$-methylene-ATP evokes very small currents though bzATP, $\beta, \gamma$-imido-ATP or other nucleotides triphosphates elicit no response (Fountain et al., 2008). The antagonist profile of OtP2X is similar to that of the Dictyostelium $\mathrm{P} 2 \mathrm{X}$ receptors with suramin, PPADS and TNP-ATP all failing to cause block up to $100 \mu \mathrm{M}$. Unlike the Dictyostelium $\mathrm{P} 2 \mathrm{X}$ receptor, OtP2X receptor currents are unaffected by $\mathrm{Cu}^{2+}$ upto $100 \mu \mathrm{M}$.

In contrast to other $\mathrm{P} 2 \mathrm{X}$ receptors, Ot $\mathrm{P} 2 \mathrm{X}$ displays poor calcium permeability $\left(P_{\mathrm{Ca}} / \mathrm{P}_{\mathrm{Na}}=0.4\right)$. The poor permeation of calcium is a result of a major structural difference between $O t \mathrm{P} 2 \mathrm{X}$ and mammalian receptors, i.e., the absence of an aspartate residue that is highly conserved amongst other primitive and mammalian $\mathrm{P} 2 \mathrm{X}$ receptors in the second transmembrane domain, the conserved aspartate is replaced by an asparagine residue. $\mathrm{Asn}^{353}$ in Ot $\mathrm{P} 2 \mathrm{X}$ is equivalent to $\mathrm{Asp}^{349}$ in rat $\mathrm{P} 2 \mathrm{X}_{2}$. Though a switch from an acidic to a basic moiety can clearly be tolerated at this position in OtP2X,a $[\mathrm{N} 353 \mathrm{~A}]$ mutation renders the receptor non-functional (Fountain et al., 2008). OtP2X[N353R] enhances the calcium permeability $\left(P_{\mathrm{Ca}} / \mathrm{P}_{\mathrm{Na}}=0.64\right.$; Fountain et al., 2008) but not back to the level of mammalian $\mathrm{P} 2 \mathrm{X}$ receptors. This suggests other residues in mammalian $\mathrm{P} 2 \mathrm{X}$ receptors also contribute to high calcium permeability (Migita et al., 2001; Samways and Egan, 2007). The pore diameter of $\mathrm{O} t \mathrm{P} 2 \mathrm{X}$ receptors estimated from the relative permeability of a range of cations suggests a permeability cut-off of $1 \mathrm{~nm}$. This broadly agrees with estimates of mammalian and Dictyostelium P2X receptor pore sizes (Evans et al., 1996; Fountain et al., 2007) and suggests architectural conservation of the selectivity filter between very early $\mathrm{P} 2 \mathrm{X}$ receptor proteins and mammalian $\mathrm{P} 2 \mathrm{X}$ receptors.
Though $\mathrm{OtP} 2 \mathrm{X}$ is clearly expressed at the plasma membrane when overexpressed in HEK293 cells, the subcellular localization of $\mathrm{Ot} \mathrm{P} 2 \mathrm{X}$ in O. tauri has not been confirmed. Such experiments are hampered but the lack of selective antibodies to $\mathrm{OtP} 2 \mathrm{X}$ and the size of the organism (around $1 \mu \mathrm{M}$ in diameter) not being amenable to conventional immunocytochemical studies. However, experiments to determine whether ATP can induce calcium entry in O. tauri suspended in artificial sea water provide some indirect data supporting a lack of cell surface expression of P2X receptors. Though ATP does not stimulate calcium influx micromolar capsaicin, the TRPV1 channel agonist, did stimulate influx. A TRPV1 homologue is encoded by this primitive algae.

\section{Monosiga brevicollis (Choanoflagelate)}

Choanoflagelates are free living unicellular and colonial flagellate eukaryotes considered the closest living relative of animal cells. Fountain et al. (2008) reported cloning of a P2X receptor homologue from $M$. brevicollis. The $M b \mathrm{P} 2 \mathrm{X}$ receptor formed functional ATP activated ion channels when expressed in HEK293, though a pharmacological and biophysical characterization has not yet been published.

\section{TARDIGRADE (Hypsibius dujardini)}

Hypsibius dujardini belongs to the phylum Tardigrade that shares features common to nematodes and arthropods. Around $400 \mu \mathrm{M}$ in length, these multicellular organisms inhabit moss and freshwater environments, and are capable of lowering their metabolism enough to survive desiccating environments for long periods. Bavan etal. (2009) identified a 330 bp EST from $H$. dujardini which when translated shared homology with mammalian P2X receptors. The full-length coding region translates to a 480 amino acid protein $(H d \mathrm{P} 2 \mathrm{X})$ that shares between 36 and $38 \%$ sequence homology with human $\mathrm{P}_{2} \mathrm{X}_{1}, \mathrm{P}_{2} \mathrm{X}_{3}$, and $\mathrm{P} 2 \mathrm{X}_{4}$. Phylogenic analysis suggests $H d \mathrm{P} 2 \mathrm{X}$ is an ancestor of vertebrate $\mathrm{P} 2 \mathrm{X}$ receptors and orthologous to other non-vertebrate receptors including Dictyostelium, S. Mansoni and O. tauri. Expression of HdP2X cRNA in Xenopus oocytes produces ATP ( $\mathrm{EC}_{50} 45 \mu \mathrm{M}$ ) activated ion channels that mediate transient inward currents that rapidly desensitizes in the presence of ligand. Despite this rapid desensitization and in contrast to the human $\mathrm{P}_{2} \mathrm{X}_{1}$ receptor that also displays rapid desensitization during ATP application, HdP2X currents recover. Current amplitude is fully recovered following $5 \mathrm{~min}$ agonist wash-off. HdP2X can be activated by both BzATP and $\alpha \beta$-methylene-ATP. BzATP acts as a partial agonist at $H d \mathrm{P} 2 \mathrm{X}$ with maximal concentrations producing around $65 \%$ of ATP. Though BzATP is less efficacious it acts more potently than ATP with an $\mathrm{EC}_{50}$ around $12 \mu \mathrm{M} . \alpha, \beta$-methylene-ATP is less efficacious than ATP and evokes current amplitudes that are 50\% of ATP responses. BzATP potency and efficacy with regard to ATP at $H d P 2 \mathrm{X}$ mirror that of BzATP properties at SchP2X receptors (Agboh et al., 2004).

$H d \mathrm{P} 2 \mathrm{X}$ is blocked by the broad-spectrum purinergic receptor antagonists PPADs ( $\left.\mathrm{IC}_{50} 15 \mu \mathrm{M}\right)$ and Suramin ( $\left.\mathrm{IC}_{50} 23 \mu \mathrm{M}\right)$, which is in contrast to other primitive $\mathrm{P} 2 \mathrm{X}$ receptors that are insensitive to classical antagonists. Micromolar $\mathrm{Cu}^{2+}$ and $\mathrm{Zn}^{2+}$ block HdP2X. Divalent metal ions modulate mammalian P2X receptor function and the Dictyostelium $\mathrm{P} 2 \mathrm{X}_{\mathrm{A}}$ receptor. $\mathrm{Cu}^{2+}$ and $\mathrm{Zn}^{2+}$ inhibit ATP-evoked responses with an $\mathrm{IC}_{50}$ of 20 and 
$63 \mu \mathrm{M}$, respectively. In mammalian $\mathrm{P} 2 \mathrm{X}_{2}$ and $\mathrm{P} 2 \mathrm{X}_{7}$ the modulatory activity of $\mathrm{Cu}^{2+}$ is mediated through interaction with histidine residues in the ectodomain. Bavan et al. (2009) produced histidine-to-alanine mutant $H d \mathrm{P} 2 \mathrm{X}$ receptors to investigate a role in divalent metal ion action. Though $H d \mathrm{P} 2 \mathrm{X}$ inhibition by $\mathrm{Zn}^{2+}$ was unaffected by alanine substitution of ectodomain histidine residues, the effectiveness of $\mathrm{Cu}^{2+}$ block was limited in $\mathrm{HdP} 2 \mathrm{X}[\mathrm{H} 252 \mathrm{~A} / \mathrm{H} 306 \mathrm{~A}]$ and [H232A/H306A] double mutants suggesting a role for these residues in coordinating $\mathrm{Cu}^{2+}$ action. ATP evoked currents mediated by $H d 2 \mathrm{X}$ are potentiated by the macrocyclic lactone ivermectin which also potentiates mammalian $\mathrm{P}_{2} \mathrm{X}_{4}$ and $S$. mansoni receptors.

\section{Lymnaea stagnalis (POND SNAIL)}

The pond snail Lymnaea stagnalis has proven a useful model to study fundamental aspects of the CNS. Its relatively simple CNS contains $<22,000$ neurons making it amenable to study processes of associative memory and taste. ATP release in molluscan CNS has been studied in real-time (Gruenhagen et al., 2004) highlighting a potential for purinergic receptors in invertebrate CNS function. A full-length P2X receptor orthologue has been cloned from $L$. stagnalis CNS (LymP2X). LymP2X is 435 amino acids in length and shares $31-46 \%$ identity with human $\mathrm{P}_{2} \mathrm{X}_{1}-\mathrm{P} 2 \mathrm{X}_{7}$, sharing most similarity with the human $\mathrm{P}_{2} \mathrm{X}_{4}$ receptor. Lym $\mathrm{P} 2 \mathrm{X}$ expressed in Xenopus oocytes mediates inward currents that can be activated by ATP, BzATP and $\alpha, \beta$-methylene-ATP. ATP is a full agonist that produces half-maximal responses at $6 \mu \mathrm{M}$. BzATP is 3-fold more potent $\left(\mathrm{EC}_{50} 2 \mu \mathrm{M}\right)$ than ATP at $L y m \mathrm{P} 2 \mathrm{X}$ but acts as a partial agonist, producing a maximal response $66 \%$ that of ATP maximal response. $\alpha, \beta$-methylene-ATP acts as a weak agonist. LymP2X is blocked by both PPADS and suramin. PPADS can completely block ATP evoked currents above $100 \mu \mathrm{M}$ and has a half-maximal inhibitory concentration of $8 \mu \mathrm{M}$. Suramin is less effective with an $\mathrm{IC}_{50}$ of $27 \mu \mathrm{M}$ and produces incomplete channel block even at a concentration of $300 \mu \mathrm{M}$. The suramin resistant component accounts for around $40 \%$ of maximum currant (Bavan et al., 2012). LymP2X currents are not potentiated by ivermectin but are potentiated by $100 \mu \mathrm{M} \mathrm{Cu}^{2+}$ or $\mathrm{Zn}^{2+}$. The level of potentiation is between 45 and $75 \%$. However, the effect of divalent metal ions is biphasic as $1 \mathrm{mM} \mathrm{Cu}^{2+}$ or $\mathrm{Zn}^{2+}$ inhibits the receptor by around $65 \%$. The CNS of Lymnaea has several discernable ganglia including buccal, cerebral, pedal, pleural, left parietal, right parietal, and visceral ganglia. In situ hybridization reveals widespread expression of LymP2X in neurons of all ganglia, though quantitation of LymP2X mRNA transcripts reveals highest expression in neurons of pedal ganglia and the lowest levels in pleural neurons (Bavan et al., 2012). Though a physiological role of LymP2X is yet to be assigned, it is highly likely that the receptor is placed to respond to ATP secreted by neurons or supporting cells of the mollusc CNS.

\section{Boophilus microplus (TICK)}

The B. microplus tick causes detrimental effects to cattle wellbeing through blood feeding and transmission of disease. The tick $\mathrm{P} 2 \mathrm{X}$ receptor homologue $\mathrm{Bm} \mathrm{P} 2 \mathrm{X}$ forms a functional ATP activated ion channel when expressed in xenoupus oocytes (Bavan et al., 2011). The 414 amino acid long receptor shares between 30 and $44 \%$ sequence identity with human receptors, sharing the most identity with human $\mathrm{P}_{2} \mathrm{X}_{4}$ and least with $\mathrm{P}_{2} \mathrm{X}_{7}$. The receptor contains many structural motifs common to mammalian P2X receptors including 10 conserved ectodomain cysteines, positive and aromatic residues implicated in ATP binding and $\mathrm{N}$-terminal putative protein kinase $\mathrm{C}$ phosphorylation site. Currents passed by $B m \mathrm{P} 2 \mathrm{X}$ exhibit extremely slow kinetics. ATP evoked currents reach peak after almost $5 \mathrm{~s}$, which is in stark contrast to the millisecond activation kinetics of mammalian P2X receptors (North, 2002). Current decay in the presence of agonist are also markedly slow. BmP2X currents decay by around $10 \%$ after $20 \mathrm{~s}$ exposure to ATP with $50 \%$ decay occurring after prolonged ( $>5 \mathrm{~min}$ ) agonist application. Despite limited current decay in the presence of agonist, rundown in peak responses is marked. Consecutive ATP applications cause a $12 \%$ reduction in peak currents. Bavan et al. (2011) identified sequences positively charged residues in the C-terminus responsible for controlling receptor desensitization. Basic residues in the receptor C-terminus also control the desensitization kinetics of human $\mathrm{P} 2 \mathrm{X}$ receptors (Fountain and North, 2006). However, the C-terminus does not contribute to receptor rundown properties. ATP activates $B m \mathrm{P} 2 \mathrm{X}$ with an $\mathrm{EC}_{50}$ value of $70 \mu \mathrm{M}$, though adenosine, ADP or UTP (all up to $1 \mathrm{mM}$ ) do not evoke currents. Suramin antagonizes $B m P 2 X\left(\mathrm{IC}_{50}=5 \mu \mathrm{M}\right)$ but produces an incomplete block with currents persisting up to $300 \mu \mathrm{M}$. Ivermectin potentiates ATP evoked currents at mammalian $\mathrm{P}_{2} \mathrm{X}_{4}$ receptors (Priel and Silberberg, 2004), S. mansoni $\mathrm{P} 2 \mathrm{X}(S m \mathrm{P} 2 \mathrm{X})$ and $H$. dujarini $(H d \mathrm{P} 2 \mathrm{X})$ receptors. Despite its broad-spectrum anti-parasitic activity ivermectin does not potentiation $B m \mathrm{P} 2 \mathrm{X}$ currents. However, currents are potentiated by amitraz, a triazapentadine compound used widely in the treatment of tick infestation in cattle. Peak currents are potentiated by 23 and $94 \%$ by 1 and $100 \mu \mathrm{M}$ amitraz, respectively. The identification of $B m \mathrm{P} 2 \mathrm{X}$ is of major interest, not only as a target for potential new anti-parasitic drugs, but also as an example on an arthropod P2X receptor. Genomic information reveals that other arthropods including Drosophila melanogaster, Apis mellifera and Anopheles gambiae lack P2X receptors (Fountain and Burnstock, 2009). The existence of P2X receptors in the arthropod phylum suggests selective loss of $\mathrm{P} 2 \mathrm{X}$ receptors in some, and likely the majority, of insect species.

\section{GENERAL STRUCTURAL CONSERVATION WITH MAMMALIAN RECEPTORS}

Functional mammalian P2X receptors assemble as oligomers of three pore-forming subunits (Young etal., 2008; Kawate et al., 2009). This trimeric oligomeric state is unusual amongst other ligand-gated and voltage-gated ion channel families, including ionotropic glutamate and nicotinic acetylcholine receptors (Cysloop superfamily), but shared by ASIC and intracellular TRIC channels. Our previous work demonstrates that Dictyostelium $\mathrm{P} 2 \mathrm{X}$ assemble as trimers, at least when expressed as recombinant receptors in mammalian cells (Fountain et al., 2007), suggesting a conservation of trimer formation by primitive $\mathrm{P} 2 \mathrm{X}$ receptors. Expression of Dictyostelium P2X receptors in Sf9 insect cells also results in strong trimer formation, and the Dictyostelium receptor trimers are a similar size to that of vertebrate receptor trimers (Valente et al., 2011). The Dictyostelium P2X receptors remain the best structurally characterized primitive $\mathrm{P} 2 \mathrm{X}$ receptors. The 
low primary sequence homology with mammalian $\mathrm{P} 2 \mathrm{X}$ receptors (Fountain et al., 2007) and significantly different 3D structure (Valente et al., 2011) make them interesting candidates for future structural studies.

Ten ectodomain cysteine residues are highly conserved in mammalian P2X receptors and interact to form five disulphide bonds. The cysteines are positioned at residues C177, C126, C132, C149, C159, C165, C217, C227, C261, and C270 based on human $\mathrm{P}_{2} \mathrm{X}_{1}$ numbering. These disulphide bonds are resolved in the zebrafish P2X4 crystal structure (Kawate et al., 2009) and influence the structure of the ATP binding pocket, channel gating properties, and trafficking of mammalian receptors (Rokic et al., 2010; Jindrichova et al., 2012). The degree of ectodomain cysteine conservation in cloned primitive $\mathrm{P} 2 \mathrm{X}$ receptors varies greatly and shows no correlation with species phylogeny. Trematode (S. mansoni) and tarigrade $(H$. dujardini) receptors retain all equivalent cysteine residues, whereas algae $(O$. tauri) and choanoflagellate (M. brevicollis) receptors lack C217, C227, and C117, C165 equivalents, respectively. Based on the prediction of cysteine-cysteine pairing for disulphide bond formation in the human $\mathrm{P}_{2} \mathrm{X}_{1}$ receptor (Ennion and Evans, 2002), this would predict both the O. tauri and $M$. brevicollis receptor lack a single ectodomain disulphide bond, though at different positions. Strikingly, the Dictyostelium $\mathrm{P} 2 \mathrm{X}_{\mathrm{A}}$ receptors lacks cysteines at all equivalent position yet is a functional ATP activated ion channel (Fountain et al., 2007), suggesting a marked difference in ectodomain tertiary structure despite an ability to bind micromolar ATP (Valente et al., 2011).

\section{FUTURE PERSPECTIVES AND EXPERIMENTAL ADVANTAGES}

A growing wealth of genomic information for single celled and non-vertebrate species makes it highly likely that our knowledge of $\mathrm{P} 2 \mathrm{X}$ receptor phylogeny is set to expand rapidly. Recently several putative P2X receptor sequences were reported from sea sponge (Amphimedon queenslandica), amoeboid holozoan (Capsaspora owczarzaki) and nematode (Xiphinema index; Cai, 2012). Interestingly the same report identifies P2X orthologues in three species of basal fungi, namely Allomyces macrogynus, Spizellomyces punctatus, and Batrachochytrium dendrobatidis (Cai and Clapham, 2012). Though the function of these newly identified P2X receptors is yet to be demonstrated experimentally, these putative receptors share many of the structural hallmarks associated with $\mathrm{P} 2 \mathrm{X}$ receptor function (Cai, 2012). Their existence suggests some phyla initially thought to lack $\mathrm{P} 2 \mathrm{X}$ receptors, such as nematode and fungi (Fountain and Burnstock, 2009), may contain some species that do posses ATP activated ion channels. Identification of P2X receptors in the single celled green algae species Ostreococcus tauri demonstrate that the existence of $\mathrm{P} 2 \mathrm{X}$ receptors predates the origins of multicellularity, and that the evolution of these receptor class occurred more than 1 billion years ago. Similar sequences are also present in the genome of Osteococcus lucimarinus (Palenik et al., 2007). Though OtP2X share poor primary structure homology with mammalian $\mathrm{P} 2 \mathrm{X}$ receptors the proteins assembly to fully functional ATP activated ion channels. Elucidating the physiological role of $\mathrm{P} 2 \mathrm{X}$ receptors in such small organisms will be technically challenging but of immense interest. O. tauri are photosynthetic organisms yet to date the has been no functional or genomic evidence presented for the existence of $\mathrm{P} 2 \mathrm{X}$ receptors in higher plants. P2X receptors are notably absent from some species used extensively in neuroscience as model organisms including Caenorhabditis elegans and Drosophila melanogaster (Fountain and Burnstock, 2009). The absence of functional P2X receptors in Drosophila has been used as an experimental advantage for the study of neural circuits and behavior in this genetically amenable model organism. Ectopic expression of rat $\mathrm{P}_{2} \mathrm{X}_{2}$ in Drosophila neurons allows for channel activation by laser-stimulated uncaging of caged ATP injected into specific fly brain areas. This allows pair activation of a specific set of neurons with exposure to a second stimulus such as odor (Zemelman et al., 2003).

\section{SUMMARY}

In summary, the phylogenetic distribution of $\mathrm{P} 2 \mathrm{X}$ receptors is incomplete but demonstration of functional receptors in simple unicellular organisms suggests evolution of this receptor class occurred over one billion years ago. The fact that many primitive P2X receptors share very low sequence homology with mammalian $\mathrm{P} 2 \mathrm{X}$ receptors, including absence of key motifs, yet still retain micromolar sensitivity to ATP and common permeability properties is intriguing. Some low homology receptors which lack sensitivity to common $\mathrm{P} 2 \mathrm{X}$ receptors are likely to be useful tools in the future with which to delineate the residues that coordinate drug binding at P2X receptors. Though we have gathered much structural information from cloning and characterization of primitive P2X receptor our understanding of their cell biology and physiology is restricted, but likely to provide fundamental information about why and how the $\mathrm{P} 2 \mathrm{X}$ receptor class of ligand-gated ion channels evolved.

\section{ACKNOWLEDGMENT}

Samuel J. Fountain is supported by a BBSRC David Phillips Fellowship.

\section{REFERENCES}

Agboh, K. C., Webb, T. E., Evans, R. J., and Ennion, S. J. (2004). Functional characterization of a P2X receptor from Schistosoma mansoni. J. Biol. Chem. 279, 41650-41657. doi: 10.1074/jbc.M408203200

Baines, A., Parkinson, K., Sim, J. A., Bragg, L., Thompson, C. R., and North, R. A. (2013). Functional properties of five Dictyostelium discoideum $\mathrm{P} 2 \mathrm{X}$ receptors. J. Biol. Chem. 288, 20992-21000. doi: 10.1074/jbc.M112.445346

Bavan, S., Farmer, L., Singh, S. K., Straub, V. A., Guerrero, F. D., and Ennion, S. J. (2011). The penultimate arginine of the carboxyl terminus determines slow desensitization in a P2X receptor from the cattle tick Boophilus microplus. Mol. Pharmacol. 79, 776-785. doi: 10.1124/mol.110.070037

Bavan, S., Straub, V. A., Blaxter, M. L., and Ennion, S. J. (2009). A P2X receptor from the tardigrade species Hypsibius dujardini with fast kinetics and sensitivity to zinc and copper. BMC Evol. Biol. 9:17. doi: 10.1186/1471-2148-9-17

Bavan, S., Straub, V. A., Webb, T. E., and Ennion, S. J. (2012). Cloning and characterization of a P2X receptor expressed in the central nervous system of Lymnaea stagnalis. PLoS ONE 7:e50487. doi: 10.1371/journal.pone.0050487

Bo, X., Jiang, L. H., Wilson, H. L., Kim, M., Burnstock, G., Surprenant, A., et al. (2003). Pharmacological and biophysical properties of the human P2X5 receptor. Mol. Pharmacol. 63, 1407-1416. doi: 10.1124/mol.63.6.1407

Burnstock, G. (2012). Discovery of purinergic signalling, the initial resistance and current explosion of interest. Br. J. Pharmacol. 167, 238-255. doi: 10.1111/j.14765381.2012.02008.x

Burnstock, G., and Verkhratsky, A. (2009). Evolutionary origins of the purinergic signalling system. Acta Physiol. 195, 415-447. doi: 10.1111/j.17481716.2009.01957.x

Cai, X. (2012). P2X receptor homologs in basal fungi. Purinergic Signal. 8, 11-13. doi: $10.1007 / \mathrm{s} 11302-011-9261-8$ 
Cai, X., and Clapham, D. E. (2012). Ancestral Ca2+ signaling machinery in early animal and fungal evolution. Mol. Biol. Evol. 29, 91-100. doi: 10.1093/molbev/msr149

Chaumont, S., Jiang, L. H., Penna, A., North, R. A., and Rassendren, F. (2004). Identification of a trafficking motif involved in the stabilization and polarization of P2X receptors. J. Biol. Chem. 279, 29628-29638. doi: 10.1074/jbc.M403940200

Coddou, C., Morales, B., and Huidobro-Toro, J. P. (2003). Neuromodulator role of zinc and copper during prolonged ATP applications to P2X4 purinoceptors. Eur. J. Pharmacol. 472, 49-56. doi: 10.1016/S0014-2999(03)01864-8

Ennion, S. J., and Evans, R. J. (2002). Conserved cysteine residues in the extracellular loop of the human $\mathrm{P} 2 \mathrm{X}(1)$ receptor form disulfide bonds and are involved in receptor trafficking to the cell surface. Mol. Pharmacol. 61, 303-311. doi: 10.1124/mol.61.2.303

Evans, R. J., Lewis, C., Virginio, C., Lundstrom, K., Buell, G., Surprenant, A., et al. (1996). Ionic permeability of, and divalent cation effects on, two ATP-gated cation channels (P2X receptors) expressed in mammalian cells. J. Physiol. 497(Pt 2), 413-422.

Evans, R. J., and Surprenant, A. (1992). Vasoconstriction of guinea-pig submucosal arterioles following sympathetic nerve stimulation is mediated by the release of ATP. Br. J. Pharmacol. 106, 242-249. doi: 10.1111/j.1476-5381.1992.tb14323.x

Fountain, S. J. (2010). Neurotransmitter receptor homologues of Dictyostelium discoideum. J. Mol. Neurosci. 41, 263-266. doi: 10.1007/s12031-009-9298-0

Fountain, S. J., and Burnstock, G. (2009). An evolutionary history of P2X receptors. Purinergic Signal. 5, 269-272. doi: 10.1007/s11302-008-9127-x

Fountain, S. J., Cao, L., Young, M. T., and North, R. A. (2008). Permeation properties of a P2X receptor in the green algae Ostreococcus tauri. J. Biol. Chem. 283, 1512215126. doi: 10.1074/jbc.M801512200

Fountain, S. J., and North, R. A. (2006). A C-terminal lysine that controls human P2X4 receptor desensitization. J. Biol. Chem. 281, 15044-15049. doi: 10.1074/jbc.M600442200

Fountain, S. J., Parkinson, K., Young, M. T., Cao, L., Thompson, C. R., and North, R. A. (2007). An intracellular P2X receptor required for osmoregulation in Dictyostelium discoideum. Nature 448, 200-203. doi: 10.1038/nature05926

Gruenhagen, J. A., Lovell, P., Moroz, L. L., and Yeung, E. S. (2004). Monitoring real-time release of ATP from the molluscan central nervous system. J. Neurosci. Methods 139, 145-152. doi: 10.1016/j.jneumeth.2004.03.008

Heuser, J., Zhu, Q., and Clarke, M. (1993). Proton pumps populate the contractile vacuoles of Dictyostelium amoebae. J. Cell Biol. 121, 1311-1327. doi: 10.1083/jcb.121.6.1311

Jindrichova, M., Kuzyk, P., Li, S., Stojilkovic, S. S., and Zemkova, H. (2012). Conserved ectodomain cysteines are essential for rat $\mathrm{P} 2 \mathrm{X} 7$ receptor trafficking. Purinergic Signal. 8, 317-325. doi: 10.1007/s11302-012-9291-x

Kawate, T., Michel, J. C., Birdsong, W. T., and Gouaux, E. (2009). Crystal structure of the ATP-gated P2X(4) ion channel in the closed state. Nature 460, 592-598. doi: $10.1038 /$ nature 08198

Khakh, B. S., and North, R. A. (2006). P2X receptors as cell-surface ATP sensors in health and disease. Nature 442, 527-532. doi: 10.1038/nature04886

Kohn, A. B., Anderson, P. A., Roberts-Misterly, J. M., and Greenberg, R. M. (2001). Schistosome calcium channel beta subunits. Unusual modulatory effects and potential role in the action of the antischistosomal drug praziquantel. J. Biol. Chem. 276, 36873-36876. doi: 10.1074/jbc.C100273200

Ludlow, M. J., Durai, L., and Ennion, S. J. (2009). Functional characterization of intracellular Dictyostelium discoideum P2X receptors. J. Biol. Chem. 284, 35227 35239. doi: 10.1074/jbc.M109.045674

Ludlow, M. J., Traynor, D., Fisher, P. R., and Ennion, S. J. (2008). Purinergicmediated Ca2+ influx in Dictyostelium discoideum. Cell Calcium 44, 567-579. doi: 10.1016/j.ceca.2008.04.001

Malchow, D., Lusche, D. F., Schlatterer, C., De Lozanne, A., and MüllerTaubenberger, A. (2006). The contractile vacuole in Ca2+-regulation in Dictyostelium: its essential function for cAMP-induced Ca2+-influx. BMC Dev. Biol. 6:31. doi: 10.1186/1471-213X-6-31

Migita, K., Haines, W. R., Voigt, M. M., and Egan, T. M. (2001). Polar residues of the second transmembrane domain influence cation permeability of the ATP-gated P2X(2) receptor. J. Biol. Chem. 276, 30934-30941. doi: 10.1074/jbc.M103366200

Miklavc, P., Mair, N., Wittekindt, O. H., Haller, T., Dietl, P., Felder, E., et al. (2011). Fusion-activated $\mathrm{Ca} 2+$ entry via vesicular $\mathrm{P} 2 \mathrm{X} 4$ receptors promotes fusion pore opening and exocytotic content release in pneumocytes. Proc. Natl. Acad. Sci. U.S.A. 108, 14503-14508. doi: 10.1073/pnas.1101039108
North, R. A. (2002). Molecular physiology of P2X receptors. Physiol. Rev. 82, 1013 1067.

Palenik, B., Grimwood, J., Aerts, A., Rouzé, P., Salamov, A., Putnam, N., et al. (2007). The tiny eukaryote Ostreococcus provides genomic insights into the paradox of plankton speciation. Proc. Natl. Acad. Sci. U.S.A. 104, 7705-7710. doi: $10.1073 /$ pnas.0611046104

Parish, R. W., and Weibel, M. (1980). Extracellular ATP, ecto-ATPase and calcium influx in Dictyostelium discoideum cells. FEBS Lett. 118, 263-266. doi: 10.1016/0014-5793(80)80234-1

Priel, A., and Silberberg, S. D. (2004). Mechanism of ivermectin facilitation of human P2X4 receptor channels. J. Gen. Physiol. 123, 281-293. doi: 10.1085/jgp.200308986

Qureshi, O. S., Paramasivam, A., Yu, J. C., and Murrell-Lagnado, R. D. (2007). Regulation of $\mathrm{P} 2 \mathrm{X} 4$ receptors by lysosomal targeting, glycan protection and exocytosis. J. Cell Sci. 120(Pt 21):3838-3849. doi: 10.1242/jcs.010348

Rokic, M. B., Tvrdoňová, V., Vávra, V., Jindřichová, M., Obšil, T., Stojilkovic, S. S., et al. (2010). Roles of conserved ectodomain cysteines of the rat P2X4 purinoreceptor in agonist binding and channel gating. Physiol. Res. 59, 927-935.

Ruppelt, A., Liang, B. T., and Soto, F. (1999). Cloning, functional characterization and developmental expression of a P2X receptor from chick embryo. Prog. Brain Res. 120, 81-90. doi: 10.1016/S0079-6123(08) 63547-5

Samways, D. S., and Egan, T. M. (2007). Acidic amino acids impart enhanced Ca2+ permeability and flux in two members of the ATP-gated P2X receptor family. $J$ Gen. Physiol. 129, 245-256. doi: 10.1085/jgp.200609677

Sivaramakrishnan, V., and Fountain, S. J. (2012). A mechanism of intracellular P2X receptor activation. J. Biol. Chem. 287, 28315-28326. doi: 10.1074/jbc.M112.372565

Sivaramakrishnan, V., and Fountain, S. J. (2013). Intracellular P2X receptors as novel calcium release channels and modulators of osmoregulation in Dictyostelium: a comparison of two common laboratory strains. Channels (Austin) 7, 43-46. doi: $10.4161 /$ chan.22737

Thompson, K. E., Korbmacher, J. P., Hecht, E., Hobi, N., Wittekindt, O. H., Dietl, P., et al. (2013). Fusion-activated cation entry (FACE) via $\mathrm{P}_{2} \mathrm{X}_{4}$ couples surfactant secretion and alveolar fluid transport. FASEB J. 27, 1772-1783. doi: 10.1096/fj.12220533

Valente, M., Watterson, S. J., Parker, M. D., Ford, R. C., and Young, M. T. (2011). Expression, purification, electron microscopy, N-glycosylation mutagenesis and molecular modeling of human P2X4 and Dictyostelium discoideum P2XA. Biochim. Biophys. Acta 1808, 2859-2866. doi: 10.1016/j.bbamem.2011.08.025

Virginio, C., Church, D., North, R. A., and Surprenant, A. (1997). Effects of divalent cations, protons and calmidazolium at the rat $\mathrm{P} 2 \mathrm{X} 7$ receptor. Neuropharmacology 36, 1285-1294. doi: 10.1016/S0028-3908(97)00141-X

Young, M. T., Fisher, J. A., Fountain, S. J., Ford, R. C., North, R. A., and Khakh, B. S. (2008). Molecular shape, architecture, and size of $\mathrm{P} 2 \mathrm{X} 4$ receptors determined using fluorescence resonance energy transfer and electron microscopy. J. Biol. Chem. 283, 26241-26251. doi: 10.1074/jbc.M804458200

Zemelman, B. V., Nesnas, N., Lee, G. A., and Miesenbock, G. (2003). Photochemical gating of heterologous ion channels: remote control over genetically designated populations of neurons. Proc. Natl. Acad. Sci. U.S.A. 100, 1352-1357. doi: $10.1073 /$ pnas. 242738899

Conflict of Interest Statement: The author declares that the research was conducted in the absence of any commercial or financial relationships that could be construed as a potential conflict of interest.

Received: 14 October 2013; accepted: 19 November 2013; published online: 06 December 2013

Citation: Fountain SJ (2013) Primitive ATP-activated P2X receptors: discovery, function and pharmacology. Front. Cell. Neurosci. 7:247. doi: 10.3389/fncel.2013.00247 This article was submitted to the journal Frontiers in Cellular Neuroscience. Copyright (c) 2013 Fountain. This is an open-access article distributed under the terms of the Creative Commons Attribution License (CC BY). The use, distribution or reproduction in other forums is permitted, provided the original author(s) or licensor are credited and that the original publication in this journal is cited, in accordance with accepted academic practice. No use, distribution or reproduction is permitted which does not comply with these terms. 